\title{
Differences in Satisfaction Level of Volunteer Activities According to the General Characteristics of Volunteers
}

\author{
Nam-gyo Yun ${ }^{1}$ and Sung-je $\mathrm{Cho}^{2}$ \\ Adjunct Professor, Dept of Consumer Studies, Ewha Womans University, Korea \\ ${ }^{1}$ fy2001@naver.com, ${ }^{2}$ chosj715@daum.net
}

\begin{abstract}
The purpose of this study is to identify differences in the satisfaction level of volunteer activities according to the general characteristics of volunteers. The study was conducted on 225 volunteers in OO-gu, Seoul. For the analysis method, frequency analysis, reliability analysis, and correlation analysis were performed using the SPSS program, and t-test and one-way ANOVA for differences between groups were performed. The study found that the average difference in the satisfaction with volunteer activities based on the gender of volunteers was not significant. Second, the average difference in the satisfaction with volunteer activities according to the age of volunteers was found to be significant among the sub-components, only the assigning role value factors. Third, the average difference in the satisfaction level of volunteer activities according to a volunteer's academic background was found to be significant among the sub-components, including assigning role value factors, social recognition and health promotion factors. Fourth, the average difference in the satisfaction level of volunteer activity according to the monthly income level of volunteers was found to be insignificant. It is believed that this study will be the basis for improving conditions for improving the satisfaction of volunteers' volunteer activities.
\end{abstract}

Keywords: Satisfaction with volunteer activities, Assigning role value, Social contact, Social recognition, Health promotion

\section{Introduction}

\subsection{Necessity of research}

Volunteer activities have been expanding recently, affecting all areas of society such as youth counseling, public libraries and social welfare institutions. In particular, activating volunteer work is necessary to solve problems in the community and form a healthy community [1]. Encouraging volunteer work is very important for activating volunteer work. The reason was that volunteers' motivation to participate in volunteer work was found to have an important effect on their satisfaction with participation, and it was found that participation was an important factor in the sustainability of the volunteer work [2]. The results suggest that volunteers' motivation to participate in a personal growth factor or that the satisfaction level of volunteer work varies depending on altruistic factors.

Volunteer activities are activities that "continue to devote time and effort voluntarily without expecting specific compensation for the promotion of the welfare of the public" [3],

Article history:

Received (November 10, 2019), Review Result (December 25, 2019), Accepted (February 8, 2020) 
and these volunteer workers are called volunteers. Volunteers voluntarily participate in volunteer work to solve civil complaints in the community. These volunteer activities are significant in terms of spontaneity, non-conservatism and public nature [4]. Meanwhile, volunteer work is difficult in volunteer organizations as it is often not carried out continuously and is only temporary. This is because the number of volunteers has been increasing due to changes in social conditions in which volunteer work can be activated, whereas volunteers often stop working in the middle due to a lack of self-satisfaction [5]. In addition, according to volunteer portal statistics, the number of people participating in volunteer work increased annually until 2016 (a 27.1 percent increase over the previous year), but has been decreasing rapidly since 2017 (a 7.1 percent increase over the previous year) and 2018 (a 21.6 percent decrease over the previous year) [6]. As such, the level of volunteers' participation in volunteer work decreases very seriously.

Given these characteristics of a volunteer's free will, unless there is an environment in which the participating volunteers can continue to serve, an increasing number of volunteers will give up their volunteer service in the middle [7], thus, research is needed on factors that determine the satisfaction of volunteer activities according to their personal characteristics in order to prevent volunteers from giving up halfway and continue to volunteer activities. Given these characteristics of a volunteer's free will, it is reported to affect the sustainability and satisfaction of the volunteer work based on his or her motivations for participation, but research on the factors that determine the satisfaction of the volunteer work based on their individual characteristics is very insufficient. In other words, existing studies on volunteers consist of research on ways to sustain volunteer activities [8][9], research on sustainability and volunteer satisfaction [5], and research on motivation for volunteer participation [10][11]. In addition, most of the research on volunteers was conducted on youth counseling, public libraries, social welfare institutions, community welfare centers, etc. The preceding study on the effects of volunteer work on the satisfaction level of the general characteristics for the elderly in the next higher class is very minor.

Therefore, given the nature of the free will, such as the preceding study, it is necessary to create an environment in which participating volunteers can continue to serve. Also, research to improve self-satisfaction of volunteer work according to their personal characteristics is very necessary, based on the reported prior study results that indicated that the satisfaction of volunteer work has an impact on continuity. Therefore, this study is intended to suggest ways to reduce the number of volunteers who leave the center by revealing their effect on the satisfaction level of volunteer activities based on their individual characteristics. The purpose of the Chapter is to provide incentives to increase the sustainability of volunteer activities and to provide practical ways to intervene by improving the management of volunteer organizations for the participation of volunteers.

\subsection{Research tasks}

The purpose of this study is to analyze the differences in the satisfaction level of volunteer activities according to the general characteristics of volunteers. Specific research issues for this are as follows.

First, what is the difference in the satisfaction with volunteer work based on the gender of the volunteer?

Second, what is the difference in the satisfaction with volunteer work according to the age of the volunteers? 
Third, what is the difference in the satisfaction with volunteer work based on a volunteer's academic background?

Fourth, what is the difference in the satisfaction level of volunteer work according to the monthly income level of volunteers?

\section{Research method}

\subsection{Research subjects and tools}

The study surveyed 225 volunteers living in OO-gu, Seoul, from February 1, 2019 to May 20,2019 . The survey was conducted on a self-controlling basis after fully explaining the purpose of the survey to the study subjects in advance. A total of 225 copies of the research data were collected and used for analysis. The tools used in this study consist of four general characteristics and 16 volunteer activity satisfaction questions. The general characteristics were investigated by compiling gender, age, academic background, and monthly income levels. To measure a volunteer's satisfaction with volunteer activities, Hee-jin Kang [12] used a measuring tool for the satisfaction of volunteer activities, which consisted of a total of 16 questions, including four questions of assigning role value, four questions of social contact, four questions of social recognition, and four questions of health promotion, and each question was measured on a five-point of Likert scale.

\subsection{Confidence}

The reliability verification results of each variable used in this study were examined for each sub-factor of volunteer activity satisfaction. The reliability of the measurement tool was assured that the Cronbach's $\alpha$ value was over .60, which is the minimum level. Specific reliability analysis results are shown in [Table 1].

Table 1. Confidence of key variables

\begin{tabular}{|c|c|c|c|}
\hline \multicolumn{2}{|c|}{ Sortation } & The number of questions & Cronbach's $\alpha$ \\
\hline \multirow{3}{*}{$\begin{array}{c}\text { Satisfaction of } \\
\text { Volunteer } \\
\text { Activities }\end{array}$} & Assigning role value & 4 & .881 \\
\cline { 2 - 4 } & Social contract & 4 & .875 \\
\cline { 2 - 4 } & Social recognition & 4 & .884 \\
\cline { 2 - 4 } & Health promotion & 4 & .908 \\
\hline \multicolumn{2}{|c}{ Total } & 16 & .913 \\
\hline
\end{tabular}

\subsection{Data processing and analysis method}

Data processing collected in the study was verified at a significant level of 5\% using the SPSS 22.0 program, and the reliability calculation of each research tool was analyzed using a coefficient of Cronbach's $\alpha$. The general characteristics of volunteers were identified by conducting frequency analysis, and t-test and one-way ANOVA were conducted to find out the differences between correlation and satisfaction with volunteer activities.

\section{Research result}

\subsection{General characteristics}


Looking at the general characteristics of this study, volunteers the men's 96 (42.7 percent) and 129 women $(57.3 \%)$, the proportion of women turned out to be higher. Those in their 50s accounted for 76 (33.8 percent), followed by those in their 40 s for $50(22.2$ percent), those in their 20s and 60s for 39(17.3 percent) and those in their 30s for 21(9.3 percent). The highest number of college and college graduates was 113 (50.2 percent), followed by 60 high school graduates (26.7 percent) and 52 graduates from graduate school (23.1 percent). The monthly income level of over 4.5 million won was found to be 86 ( 38.2 percent), followed by 53 people (23.6 percent) who are over 2.5 million won and under 3.5 million won, 40 people(17.8 percent) who are over 1.5 million won and under 2.5 million won, 31 people(13.8 percent) who are over 3.5 million won and under 4.5 million won and 96 people ( 42.7 percent) who are under 1.5 million won.

\subsection{Technical statistics on major variables}

The measurement variables for the volunteers' main variables were measured on a 5-point scale. According to the sub-components of satisfaction with volunteer activities, social contact $(M=3.72)$ factors were the highest, followed by social recognition $(M=3.63)$, assigning role value $(M=3.57)$, and health promotion $(M=3.10)$. The overall satisfaction level of volunteer activity $(M=3.51)$ factor is shown to be higher than the average score.

\subsection{Correlation between variables}

The relationship between volunteer value, social contact, social recognition, and health promotion was examined. The correlation analysis results between these variables are shown in [Table 2].

Table 2. Correlation between variables

\begin{tabular}{|c|c|c|c|c|c|}
\hline \multirow{2}{*}{ Sortation } & \multicolumn{4}{|c|}{ Satisfaction of Volunteer Activities } \\
\cline { 2 - 6 } & $\begin{array}{c}\text { Assigning role } \\
\text { value }\end{array}$ & Social contract & Social recognition & Health promotion \\
\hline \multirow{4}{*}{$\begin{array}{c}\text { Satisfaction } \\
\text { of } \\
\begin{array}{c}\text { Volunteer } \\
\text { Activities }\end{array}\end{array}$} & $\begin{array}{c}\text { Assigning role } \\
\text { value }\end{array}$ & 1 & & & \\
\cline { 2 - 6 } & Social contract & $.783^{* *}$ & 1 & & \\
\cline { 2 - 6 } & Social recognition & $.753^{* *}$ & $.763 * *$ & $.682^{* *}$ & 1 \\
\hline \multirow{2}{*}{ Health promotion } & $.676^{* *}$ & $.708^{* *}$ & & \\
\hline
\end{tabular}

3.4. Differences in the satisfaction level of volunteer activities according to general characteristics

\subsubsection{Difference in the satisfaction level of volunteer activities based on the gender of volunteers}

A t-test analysis was conducted to find out the difference in the satisfaction level of volunteer activities based on the sex of volunteers. According to the analysis, sub-factors of satisfaction with volunteer activities including assigning role value $(\mathrm{p}=.059)$, social contacts $(\mathrm{p}=.919)$, social recognition $(\mathrm{p}=.311)$, health promotion $(\mathrm{p}=.663)$ were larger than .05 in 
Levene's equivalence tests and assumed to be equal variances. The average difference in the satisfaction level of volunteer activity was found to be statistically no significant difference between groups: Assigning role value $(t=1.546, p>.05)$, social contacts $(t=-.993, p>05)$, social recognition $(\mathrm{t}=-1.727, \mathrm{p}>.05)$, health promotion $(\mathrm{t}=1.716, \mathrm{p}>05)$. These results suggest that the average level of satisfaction with volunteer work that volunteers are aware of is the same regardless of gender.

\subsubsection{Differences in the satisfaction of volunteer activities by age}

A one-way ANOVA was conducted to identify differences in the satisfaction level of volunteer activities according to the age of volunteers. According to the analysis, sub-factors of satisfaction with volunteer activities including assigning role value $(\mathrm{p}=.070)$, social contacts $(\mathrm{p}=.095)$, social recognition $(\mathrm{p}=.064)$, health promotion $(\mathrm{p}=.868)$ were larger than .05 in the homogeneity tests for variances and assumed to be equal variances. For the difference in the average satisfaction level of volunteer activity, only assigning role value factors $(\mathrm{F}=2.674, \mathrm{p}<.05)$ is found to have statistically significant differences, and social contacts $(\mathrm{F}=.929, \mathrm{p}>.05)$, social recognition $(\mathrm{F}=2.412, \mathrm{p}>.05)$, and health promotion $(\mathrm{F}=1.119, \mathrm{p}>.05)$ indicates that there are no significant differences between groups. These results showed that those in their 50s had the highest assigning role value among the sub-components of volunteer activity satisfaction that volunteers are aware of. On the other hand, the average of social contact, social recognition, and health promotion factors are the same regardless of age.

\subsubsection{Differences in the satisfaction level of volunteer work based on academic background}

A one-way ANOVA was conducted to find out the difference in the satisfaction level of volunteer activities based on a volunteer's academic background. According to the analysis, sub-factors of satisfaction with volunteer activities including assigning role value $(\mathrm{p}=.081)$, social contacts $(\mathrm{p}=.261)$, social recognition $(\mathrm{p}=.101)$, health promotion $(\mathrm{p}=.776)$ were larger than .05 in the homogeneity tests for variances and assumed to be equal variances. For the average difference in the satisfaction with volunteer activities, the assigning role value $(\mathrm{F}=5.255, \mathrm{p}<.01)$, social recognition $(\mathrm{F}=4.265, \mathrm{p}<.01)$, health promotion $(\mathrm{F}=3.376, \mathrm{p}<.05)$ factors are identified as having statistically significant differences, and social contacts $(\mathrm{F}=2.239, \mathrm{p}>.05)$ factor shows no statistically significant differences. These results showed that among the sub-components of volunteer satisfaction, assigning role value, social recognition, and health promotion were highest among those who graduated from graduate school. On the other hand, the average of social contact factors is the same regardless of academic background.

\subsubsection{Differences in the satisfaction of volunteer activities according to monthly income levels}

A one-way ANOVA was conducted to identify the differences in the satisfaction with volunteer activities according to the monthly income level of volunteers. According to the analysis, sub-factors of satisfaction with volunteer activities including assigning role value $(\mathrm{p}=.226)$, social contacts $(\mathrm{p}=.098)$, social recognition $(\mathrm{p}=.066)$, health promotion $(\mathrm{p}=.662)$ were larger than .05 in the homogeneity tests for variances and assumed to be equal variances. The average difference in the satisfaction level of volunteer activity was found to be statistically no significant difference between groups (Assigning role value $(t=1.036, p>.05)$, 
social contacts $(\mathrm{t}=1.196, \mathrm{p}>05)$, social recognition $(\mathrm{t}=0.637, \mathrm{p}>.05)$, health promotion $(\mathrm{t}=0.678, \mathrm{p}>05))$. These results can be said that the assigning role value, social contact, social recognition, and health promotion factors, which are sub-components of volunteer activity satisfaction that volunteers aware of are at the same level regardless of the monthly income level.

\section{Conclusion and limitations}

In this study, the difference in the satisfaction of volunteer work was analyzed. Based on the analysis results, the detailed discussion is as follows.

First, the average difference in the satisfaction level of volunteer activities according to the gender of volunteers was found to be that there were no significant differences among groups, all of which were lower factors: assigning role value, social contact, social recognition and health promotion. Therefore, it is necessary to develop and implement various education programs in order to spread the right perception of volunteer activities socially and induce voluntary and active participation.

Second, the average difference in the satisfaction level of volunteer activities according to the age of volunteers was found to have significant differences among groups only in assigning role value factors, and social contact, social recognition and health promotion factors showed no significant differences among groups. Looking at the effects of the components of satisfaction with volunteer activities, assigning role value factors have a significant difference in volunteer activity satisfaction level according to age. The reason is judged to be the result of the fact that the assigning role value in economic and social service activities is very important for those in their 50s as a management person.

Third, the average difference in the satisfaction level of volunteer activities according to a volunteer's academic background was found to have significant differences among groups in assigning role value, social recognition and health promotion factors, but social contact factor was found to have no significant differences among groups. Based on the influence of the components of satisfaction with volunteer activities, it is judged that the reason that the factors for assigning role value, social recognition, and health promotion are significant differences in the satisfaction level of service activity according to academic background is because the higher-education person wants to gain social recognition after the loss of role and social status due to the retirement age.

Fourth, the average difference in the satisfaction level of volunteer activities according to the monthly income level of volunteers was found to be that there were no significant differences among groups, all of which were lower factors: assigning role value, social contact, social recognition and health promotion. Meaning that the satisfaction level of volunteer activity is the same regardless of the monthly income level. Since volunteers voluntarily participated in volunteer work, it is judged that there is no difference in the satisfaction of altruistic volunteer work, regardless of their monthly income level.

To summarize the limitations of this study and what needs to be supplemented in future studies:

First, this study has considerable difficulties in clearly identifying the causal relationship between the variables contained in the study model. Thus, in order to better understand the causal path between variables, future studies will need to carry out longitudinal studies exploring the causal effect between variables over time.

Second, in this study, the difference in the satisfaction level of volunteer activities according to general characteristics was used as a metric for satisfaction of volunteer 
activities, but in future research, more diverse measures such as the attitude of volunteers and psychological stability should be considered.

Third, in this study, the general characteristics of "service activity satisfaction" were reviewed as an influencing factor. In addition, however, various variables such as continuity of volunteer activities and psychological well-being are expected to affect the quality of life. Therefore, for a faithful understanding of the service activity satisfaction, it will be necessary to consider a wider and more diverse set of determinants in future studies.

\section{Acknowledgements}

I would like to thank Professor Sung-je Cho for guiding me to write this paper.

\section{References}

[1] Yoon-ro Lee and Mi-sook Cho, "Utilization of volunteers in social welfare institutions and tasks," Korea Regional Social Welfare Studies, vol.14, no.189-2, (2004)

[2] Young-shin Cho and Tae-young Cho, "The motivation of volunteer participation and effect of role conflicts on participation satisfaction and sustainability," Tourism Research, vol.30, no.5, pp.403-422, (2015)

[3] Myung-rye Kang, "A study on the persistence factors of youth volunteer activity: High school students in yeoju city graduate school of co-sung university," Ph.D. dissertation, co-sung university, (2019)

[4] Dae-gun Kim and Dong-chul Kim, "Effects of motivation for volunteer work on satisfaction and duration," GRI Research Bulletin, vol.17, no.2, pp.289-319, (2015)

[5] Sun-young Hwang, "A Study on the Determinants of Satisfaction and Continuity in Volunteer Activities," Korea Social Welfare Administration, vol.8, no.1, pp.99-124, (2006)

[6] https://www.mois.go.kr/frt/a01/frtMain.do Ministry of Government Administration and Home Affairs (1365 Resource Volunteer Portal Statistics)

[7] Geum-dan Sung and Nam-yeon Cho, "A member of the Gospel club. A Comparative Study on the Characteristics," of Volunteer Service Activities Humanities Society 21, vol.9, no.5, pp.183-193, (2018)

[8] Chang-rae Kim, "A study on the factors affecting the continuity of volunteer activities," Social Sciences Research, vol.32, no.2, pp.83-115, (2016)

[9] Jung-hun Kim, "An analysis of the factors influencing the sustainability of volunteer work," Local Government Studies, vol.14, no.3, pp.117-138, (2010)

[10] Mi-jung Gwak, "The influence of the motivation of volunteer activities on self-efficiency and psychological welfare for the elderly," Journal of Public Administration of Korea, vol.28, no.3, pp.85-107, (2014)

[11] Hee-jin Kang and Seong-je Cho, "Effects of volunteer motivation and interpersonal relationships on the satisfaction of volunteer activities," Journal of the Telecommunications Technology Association, vol.8, no.1, pp.1-8, (2015)

[12] H. J. Kang, “The influence of volunteer's emotional quotient on volunteer's voluntary work satisfaction level and psychological wellbeing: Focusing on self-efficacy mediator effect," M.S. thesis, Department of Social Welfare The Graduate School of Dongbang Culture Graduate University, (2016) 


\section{Authors}

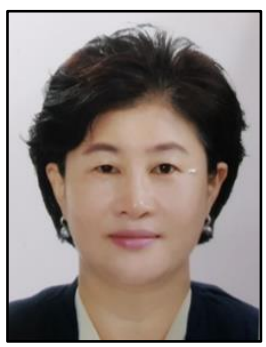

\section{Nam-gyo Yun}

Affiliation: Markers of happiness

President, CEO

Dream House301, Nonhyeonno 1-gil 6,Seocho-gu,Seoul 